\title{
Protective Effects of Duloxetine against Cerebral Ischemia- Reperfusion Injury via Transient Receptor Potential Melastatin 2 Inhibition $\$$
}

\author{
Takahiro Toda, Shinichiro Yamamoto, Noriko Umehara, Yasuo Mori, Minoru Wakamori, \\ and Shunichi Shimizu
}

\begin{abstract}
Division of Pharmacology, Faculty of Pharmaceutical Sciences, Teikyo Heisei University, Tokyo, Japan (T.T., S.Y., S.S.); Department of Oral Biology, Graduate School of Dentistry, Tohoku University, Sendai, Japan (N.U., M.W.); and Department of Synthetic Chemistry and Biological Chemistry, Graduate School of Engineering, Kyoto University, Kyoto, Japan (Y.M.)
\end{abstract}

Received September 25, 2018; accepted December 3, 2018

\section{ABSTRACT}

Activation of transient receptor potential melastatin 2 (TRPM2), an oxidative stress-sensitive $\mathrm{Ca}^{2+}$-permeable channel, contributes to the aggravation of cerebral ischemia-reperfusion (CIR) injury. Recent studies indicated that treatment with the antidepressant duloxetine for 24 hours (long term) attenuates TRPM2 activation in response to oxidative stress in neuronal cells. To examine the direct effects of antidepressants on TRPM2 activation, we examined their short-term (0-30 minutes) treatment effects on $\mathrm{H}_{2} \mathrm{O}_{2}$-induced TRPM2 activation in TRPM2expressing human embryonic kidney 293 cells using the $\mathrm{Ca}^{2+}$ indicator fura-2. Duloxetine exerted the strongest inhibitory effects on TRPM2 activation among the seven antidepressants tested. These inhibitory effects appeared to be due to the inhibition of $\mathrm{H}_{2} \mathrm{O}_{2}$-induced TRPM2 activation via an open-channel blocking-like mechanism, because duloxetine reduced the sustained phase but not the initial phase of increases in intracellular $\mathrm{Ca}^{2+}$ concentrations. In a whole-cell patch-clamp study, duloxetine reduced the TRPM2-mediated inward current during the channel opening state. We also examined the effects of duloxetine in a mouse model of CIR injury. The administration of duloxetine to wild-type mice attenuated CIR injury, similar to that in Trpm 2 knockout (KO) mice. The administration of duloxetine did not reduce CIR injury further in Trpm2 $\mathrm{KO}$ mice, suggesting that it exerts neuroprotective effects against CIR injury by inhibiting TRPM2 activation. Regarding drug repositioning, duloxetine may be a useful drug in reperfusion therapy for ischemic stroke because it has already been used clinically in therapeutics for several disorders, including depression.

\section{Introduction}

Ischemic stroke is a common cause of mortality and longterm disability. Cerebral ischemia alters normal cellular function, which is followed by neuronal cell death. Although reperfusion is critical for the rescue of neuronal cells from ischemia, it also results in the progression of neuronal cell damage because of the production of a large amount of reactive oxygen species (ROS) and inflammation with the infiltration of inflammatory cells (Chan, 2001; Granger and Kvietys, 2015; Zhang et al., 2016). Accumulating evidence has shown that the increase in intracellular $\mathrm{Ca}^{2+}$ concentrations $\left(\left[\mathrm{Ca}^{2+}\right]_{\mathrm{i}}\right)$ during reperfusion is a common key mechanism for the induction of neuronal cell death and aggravation of inflammation (Wu et al., 2010; Granger and Kvietys, 2015; Belrose and Jackson, 2018).

This work was supported in part by a Grant-in-Aid for Scientific Research on Innovative Areas [Grant 15H01409] from the Japan Society for the Promotion of Science and the Ministry of Education, Culture, Sports, Science and Technology.

https://doi.org/10.1124/jpet.118.253922.

S This article has supplemental material available at jpet.aspetjournals.org.
Transient receptor potential melastatin 2 (TRPM2) is a $\mathrm{Ca}^{2+}$-permeable nonselective cation channel that is activated by oxidative stress induced by ROS, such as $\mathrm{H}_{2} \mathrm{O}_{2}$ (Hara et al., 2002). TRPM2 possesses a NudT9-H domain in its $\mathrm{C}$ terminus that binds intracellular ADP-ribose, leading to activation of TRPM2 (Perraud et al., 2001). $\mathrm{H}_{2} \mathrm{O}_{2}$-induced TRPM2 activation is mediated by ADP-ribose production via the poly(ADP-ribose) polymerase-1/poly(ADP-ribose) glycohydrolase pathway (Fonfria et al., 2004; Buelow et al., 2008). TRPM2 expression has been detected in the brain, lungs, pancreas, and inflammatory cells such as monocytes, macrophages, and neutrophils (Perraud et al., 2001; Hara et al., 2002; Wehage et al., 2002; Nazıroğlu et al., 2012). TRPM2-evoked $\left[\mathrm{Ca}^{2+}\right]_{\mathrm{i}}$ increases have been shown to induce cell death in various types of cells, including neuronal cells (Hara et al., 2002; Kaneko et al., 2006; Verma et al., 2012). Another major physiologic role of TRPM2 is to regulate the signal cascades leading to chemokine production in monocytes and macrophages. We previously reported that activation of TRPM2 in monocytes stimulated secretion of chemokine (C-X-C motif) ligand CXCL8/CXCL2 and enhanced inflammation

ABBREVIATIONS: $\left[\mathrm{Ca}^{2+}\right]_{\mathrm{i}}$, intracellular $\mathrm{Ca}^{2+}$ concentration; $\mathrm{CIR}$, cerebral ischemia-reperfusion; G418, geneticin disulfate; HEK, human embryonic kidney; KO, knockout; ROS, reactive oxygen species; TRPA, transient receptor potential ankyrin; TRPM, transient receptor potential melastatin; TRPV, transient receptor potential vanilloid; TTC, 2,3,5-triphenyltetrazolium chloride; WT, wild type. 
(Yamamoto et al., 2008; Shimizu et al., 2015). Furthermore, recent studies implicated activation of TRPM2 channels in the aggravation of cerebral ischemia-reperfusion (CIR) injury (Jia et al., 2011; Gelderblom et al., 2014; Shimizu et al., 2016; Huang et al., 2017).

Akpinar et al. (2014) suggested that the antidepressants agomelatine and duloxetine exert inhibitory effects on $\mathrm{H}_{2} \mathrm{O}_{2}-$ induced TRPM2 activation in PC12 cells in a long-term treatment (24 hours). Demirdaş et al. (2017) recently demonstrated that the ADP-ribose-induced TRPM2 current was attenuated in the dorsal root ganglion by a long-term treatment (24 hours) with duloxetine. Thus, duloxetine exerts inhibitory effects on TRPM2 channels in cells exposed to long-term treatments. However, the direct effects of duloxetine on TRPM2 channels remain unknown.

The purpose of this study was to clarify the direct inhibitory effects of antidepressants, including duloxetine, on $\mathrm{H}_{2} \mathrm{O}_{2}$ induced TRPM2 activation and to investigate whether antidepressants, which inhibit TRPM2 activation, attenuate CIR injury in a mouse model. The goal of this study was to show that antidepressants have potential as a useful drug in reperfusion therapy for ischemic stroke.

\section{Materials and Methods}

Materials. Agomelatine, duloxetine, imipramine, milnacipran, fura-2 acetoxymethyl ester, and $\mathrm{H}_{2} \mathrm{O}_{2}$ (30\% solution) were purchased from Wako Pure Chemical Corporation (Osaka, Japan). Paroxetine, fluvoxamine, and 2,3,5-triphenyltetrazolium chloride (TTC) were purchased from Sigma-Aldrich (Tokyo, Japan). Nortriptyline was purchased from MP Biomedicals (Illkirch, France). Isoflurane was purchased from Mylan (Osaka, Japan). Alteplase was purchased from Tanabe Mitsubishi Pharma (Tokyo, Japan). All other reagents were of the highest grade and commercially available.

Reagent Preparation. In in vitro studies, all reagents were dissolved in dimethylsulfoxide in $\times 1000$ stock solution. The stock solutions were diluted in HEPES-buffered saline containing $107 \mathrm{mM}$ $\mathrm{NaCl}, 6 \mathrm{mM} \mathrm{KCl}, 1.2 \mathrm{mM} \mathrm{MgSO}_{4}, 2 \mathrm{mM} \mathrm{CaCl}_{2}, 11.5 \mathrm{mM}$ glucose, and $20 \mathrm{mM}$ HEPES, which was adjusted to $\mathrm{pH} 7.4$ using $\mathrm{NaOH}$, before use. In in vivo studies, antidepressants were dissolved in saline and administered intraperitoneally to mice used in this study. The administration volume was $10 \mathrm{ml} / \mathrm{kg}$ body weight.

Cell Culture. Human embryonic kidney (HEK) 293 cells (RIKEN Cell Bank, Tsukuba, Japan) were cultured in Dulbecco's modified Eagle's medium containing $10 \%$ fetal bovine serum, $100 \mathrm{U} / \mathrm{ml}$ penicillin, and $100 \mu \mathrm{g} / \mathrm{ml}$ streptomycin.

Stable Expression of Transient Receptor Potential Channels in HEK 293 Cells. Transfection of recombinant plasmid human TRPM2/pCMV-TAG4, transient receptor potential ankyrin 1 (TRPA1)/pCI-neo, transient receptor potential vanilloid 1 (TRPV1)/ pCI-neo, and TRPM8/pCI-neo into HEK cells was performed using the Amaxa electroporation system with the Cell Line Nucleofector Kit V (Amaxa Inc., Gaithersburg, MD) as described previously (Ishii et al., 2007). After electroporation, cells were incubated in culture medium containing $500 \mu \mathrm{g} / \mathrm{ml}$ geneticin disulfate (G418). Surviving cells were cloned and cultured, and stable TRPM2-, TRPA1-, TRPV1-, and TRPM8-expressing clones were generated (TRPM2/HEK, TRPA1/HEK, TRPV1/HEK, and TRPM8/HEK cells, respectively).

Measurement of $\left[\mathrm{Ca}^{2+}\right]_{\mathbf{i}}$. Changes in $\left[\mathrm{Ca}^{2+}\right]_{\mathrm{i}}$ were measured at $30^{\circ} \mathrm{C}$ using fura-2 as a $\mathrm{Ca}^{2+}$ indicator, as described previously (Shimizu et al., 2006; Toda et al., 2016). Briefly, cells were transferred to coverslips precoated with poly(L-lysine) (BD Biosciences, Bedford, $\mathrm{MA}$ ), and they were loaded with $5 \mu \mathrm{M}$ fura-2 acetoxymethyl ester in culture medium containing $10 \%$ fetal bovine serum at $37^{\circ} \mathrm{C}$ for 40 minutes. Cells were then washed with HEPES-buffered saline.
Coverslips were placed in a perfusion chamber mounted on an inverted microscope. Fura-2 fluorescence images of cells were then recorded at 10 -second intervals and were analyzed using a video image analysis system (Mete Fluor; Nippon Roper, Tokyo, Japan). Fluorescence at $510 \mathrm{~nm}$ (bandwidth: $50 \mathrm{~nm}$ ) was observed after the alternate excitation of fura- 2 at $340 \mathrm{~nm}$ (bandwidth, $10 \mathrm{~nm}$ ) and $380 \mathrm{~nm}$ (bandwidth, $13 \mathrm{~nm}$ ). Results are presented as a measure of the F340/F380 ratio or $\Delta$ F340/F380 ratio.

Electrophysiology. Currents were recorded using whole-cell patch-clamp techniques (Hamill et al., 1981) with an EPC-10 patchclamp amplifier (HEKA, Pfalz, Germany) at room temperature. Patch pipettes were made from borosilicate glass capillaries (outer diameter, $1.5 \mathrm{~mm}$; Hilgenberg, Malsfeld, Germany) using a model P-87 FlamingBrown micropipette puller (Sutter Instrument, San Rafael, CA). Pipette resistance ranged between 2 and $3.5 \mathrm{M} \Omega$ when filled with the pipette solution described below. Cell capacitance was $23.9 \pm$ $3.7 \mathrm{pF}(n=8)$. Currents were sampled at $1 \mathrm{kHz}$. The pipette solution contained $105 \mathrm{mM} \mathrm{CsOH}, 105 \mathrm{mM}$ aspartic acid, $40 \mathrm{mM} \mathrm{CsCl}, 2 \mathrm{mM}$ $\mathrm{MgCl}_{2}, 1.3 \mathrm{mM} \mathrm{CaCl} 2,5 \mathrm{mM}$ EGTA, $2 \mathrm{mM} \mathrm{Na} 2 \mathrm{ATP}$, and $5 \mathrm{mM}$ HEPES, adjusted to $\mathrm{pH} 7.2$ with $\mathrm{CsOH}$. The calculated free $\mathrm{Ca}^{2+}$ concentration was $50 \mathrm{nM}$. The $2 \mathrm{mM} \mathrm{Ca}^{2+}$ external solution contained $125 \mathrm{mM} \mathrm{NaCl}, 1.2 \mathrm{mM} \mathrm{MgCl}_{2}, 2 \mathrm{mM} \mathrm{CaCl}_{2}, 10 \mathrm{mM}$ glucose, $26 \mathrm{mM}$ mannitol, and $11.5 \mathrm{mM}$ HEPES, adjusted to $\mathrm{pH} 7.4$ with $\mathrm{NaOH}$. The $0 \mathrm{mM} \mathrm{Ca}^{2+}$ external solution contained $121.7 \mathrm{mM} \mathrm{NaCl}, 1.2 \mathrm{mM}$ $\mathrm{MgCl}_{2}, 1.2 \mathrm{mM} \mathrm{CaCl}_{2}, 2 \mathrm{mM}$ EGTA, $10 \mathrm{mM}$ glucose, $24 \mathrm{mM}$ mannitol, and $11.5 \mathrm{mM}$ HEPES, adjusted to $\mathrm{pH} 7.4$ with $\mathrm{NaOH}$ (calculated free $\mathrm{Ca}^{2+}$ concentration, $90 \mathrm{nM}$ ). The rapid exchange of external solutions surrounding the cell was performed within 1 second using a modified "Y-tube" method (Hara et al., 2002).

Animals. Generation of Trpm $2 \mathrm{KO}$ mice was described previously (Yamamoto et al., 2008). Male Trpm2 KO and littermate wild-type (WT) mice (C57BL/6J background, 6-9 weeks of age) were used in this study and handled in accordance with the U.S. National Institutes of Health Guide for the Care and Use of Laboratory Animals. The Experimental Animal Committee of Teikyo Heisei University approved the experimental protocol (no. 29-053).

CIR Model. CIR was induced as described previously (Shibata et al., 2010; Hashimoto et al., 2014). In this thrombus stroke model, the thrombus has been shown to travel up to the middle cerebral artery. Briefly, mice were anesthetized with $2 \%$ isoflurane. Under anesthesia, the left common carotid artery was exposed carefully from the surrounding tissue. The left common carotid artery was temporarily clamped using an aneurysm clip, and acetic acid was then applied to generate a thrombus. After 10 minutes, the clip was removed, and the thrombus was transferred to the brain for embolization by the bloodstream. Three hours after embolization, mice were administered alteplase $(10 \mathrm{mg} / \mathrm{kg}$, i.v.) for reperfusion. Twenty-one hours after reperfusion, neurologic dysfunction was measured, and the blood and brain were then collected under anesthesia with $2 \%$ isoflurane.

Assessment of Cerebral Infarct Sizes. The brain was sectioned coronally into four 2 -mm sections. All slices were stained with $2 \%$ TTC in saline at $37^{\circ} \mathrm{C}$ for 30 minutes. Each slice was then photographed on the posterior surface of each section, and the TTC-unstained white area of the whole brain was measured as the infarct area. Infarct sizes calculated from all slices were expressed as the percentage of the whole brain area (infarction area of the whole brain/area of the whole brain).

Evaluation of Neurologic Dysfunction. Neurologic scores were obtained by a modified method described previously (Longa et al., 1989; Shibata et al., 2010). The indexes used were as follows: 0, no deficit; 1 , decreased resistance to a lateral push; 2, unilateral circling; 3 , failing to the right; and 4 , no spontaneous walking with a depressed level of consciousness.

Statistical Analysis. Results are expressed as the mean \pm S.E.M. In $\mathrm{Ca}^{2+}$ imaging experiments, $n$ indicates the experimental number (average of 30-55 cells/experiment) in each measurement. Mean data were compared using an unpaired $t$ test for two groups, and multiple 
<smiles>CNCC[C@H](Oc1ccc2ccccc2c1)c1cccs1</smiles>

\section{duloxetine}<smiles>CNCCC=C1c2ccccc2CCc2ccccc21</smiles>

nortriptyline<smiles>COc1ccc2cccc(CCNC(C)=O)c2c1</smiles><smiles>CCN(CC)C(=O)C1(c2ccccc2)CC1CN</smiles><smiles>CN(C)CCCN1c2ccccc2CCc2ccccc21</smiles>

\section{agomelatine}<smiles>Fc1ccc([C@H]2CCNCC2COc2ccc3c(c2)OCO3)cc1</smiles>

paroxetine<smiles>COCCCCC(=NOCCN)c1ccc(C(F)(F)F)cc1</smiles>

fluvoxamine
Fig. 1. Chemical structures of antidepressants tested in this study. comparisons were made using an analysis of variance with the Bonferroni $t$ test. Differences were considered to be significant when $P<0.05$.

\section{Results}

Effects of Antidepressants on $\mathrm{H}_{2} \mathrm{O}_{2}$-Induced $\left[\mathrm{Ca}^{2+}\right]_{\mathrm{i}}$ Increases in TRPM2/HEK Cells. The chemical structures of the seven antidepressants tested are shown in Fig. 1.
The addition of $100 \mu \mathrm{M} \mathrm{H} \mathrm{H}_{2} \mathrm{O}_{2}$ induced sustained $\left[\mathrm{Ca}^{2+}\right]_{\mathrm{i}}$ increases in TRPM2/HEK cells, but not in HEK cells (Fig. 2A), indicating that these $\left[\mathrm{Ca}^{2+}\right]_{\mathrm{i}}$ increases were mediated by TRPM2. The addition of ionomycin after $\mathrm{H}_{2} \mathrm{O}_{2}$ treatment further increased $\left[\mathrm{Ca}^{2+}\right]_{\mathrm{i}}$ in TRPM2/HEK cells, and $\mathrm{H}_{2} \mathrm{O}_{2}$-induced $\left[\mathrm{Ca}^{2+}\right]_{\mathrm{i}}$ increases accounted for $63 \%$ of ionomycin-induced $\left[\mathrm{Ca}^{2+}\right]_{i}$ increases (Supplemental Fig. 1, A and B). The addition of carbachol after $\mathrm{H}_{2} \mathrm{O}_{2}$ treatment slightly increased $\left[\mathrm{Ca}^{2+}\right]_{\mathrm{i}}$, but it was not statistically significant
A

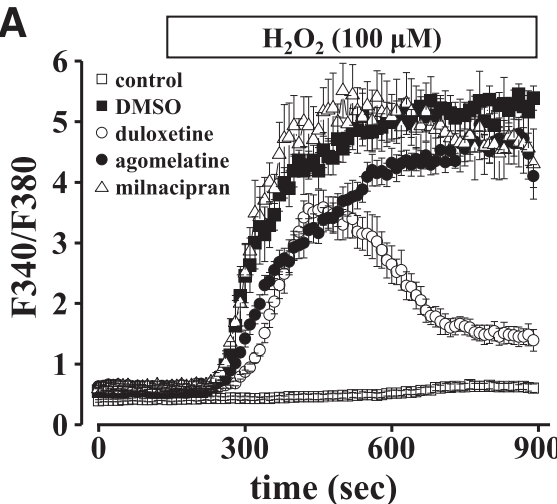

B

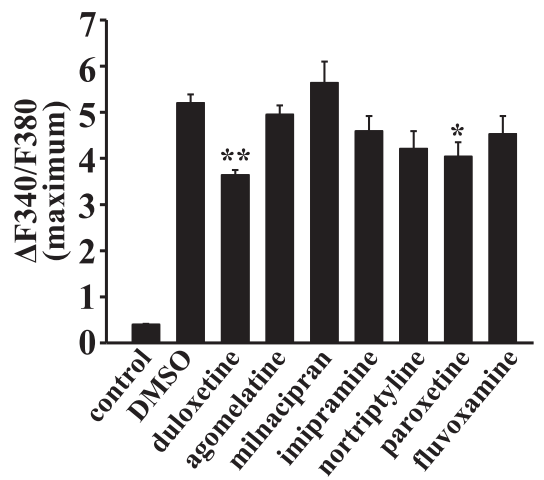

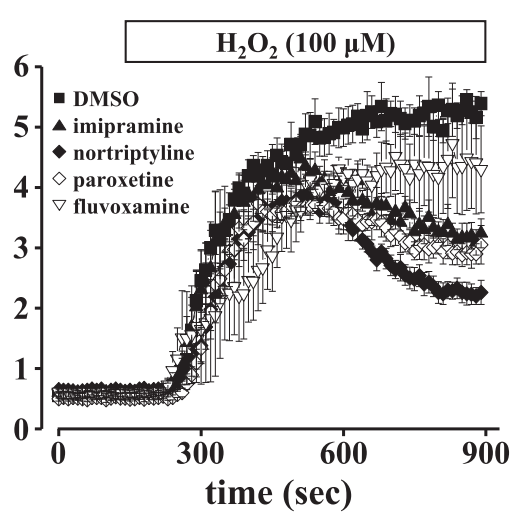

C

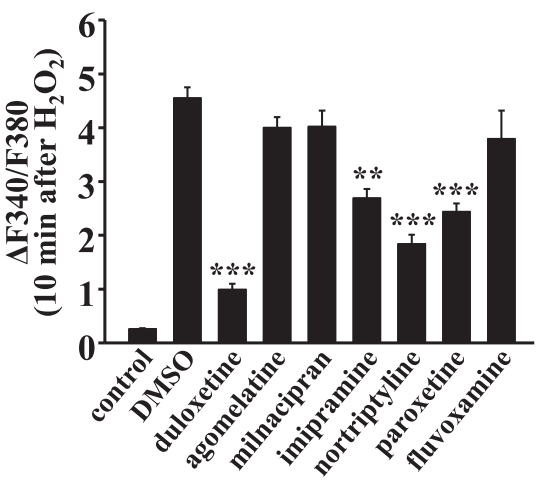

Fig. 2. Effects of antidepressants on $\mathrm{H}_{2} \mathrm{O}_{2}$-induced $\left[\mathrm{Ca}^{2+}\right]_{\mathrm{i}}$ increases in TRPM2/HEK cells. (A) HEK cells were pretreated with $0.1 \%$ DMSO (control). TRPM2/HEK cells were pretreated with $0.1 \%$ DMSO or $10 \mu \mathrm{M}$ of each antidepressant. Cells were then treated with $\mathrm{H}_{2} \mathrm{O}_{2}$ $(100 \mu \mathrm{M})$ in the presence of these compounds. (B) Delta ratios $(\Delta \mathrm{F} 340 / \mathrm{F} 380)$ at maximum responses were calculated from (A). (C) Delta ratios ( $\Delta$ F340/F380) 10 minutes after the addition of $\mathrm{H}_{2} \mathrm{O}_{2}$ were calculated from (A). Results are shown as the mean \pm S.E.M. of four experiments. $* P<0.05 ; * P<0.01$; $* * P<0.001$ vs. the DMSO group. DMSO, dimethylsulfoxide. 
A
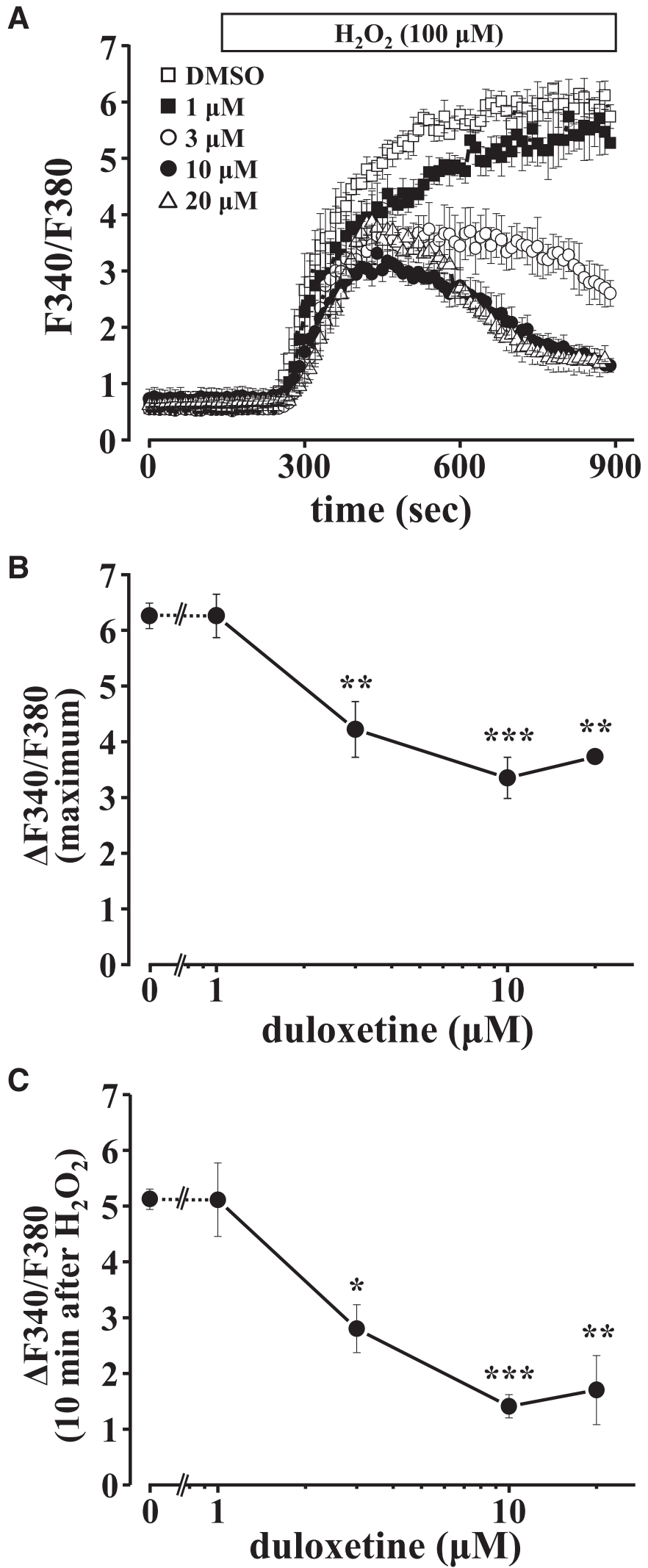

Fig. 3. Concentration-dependent inhibition of $\mathrm{H}_{2} \mathrm{O}_{2}$-induced TRPM2 activation by duloxetine. (A) TRPM2/HEK cells were pretreated with $0.1 \%$ DMSO or various concentrations of duloxetine $(1-20 \mu \mathrm{M})$ for 10 minutes, and $\mathrm{H}_{2} \mathrm{O}_{2}(100 \mu \mathrm{M})$ was then added in the presence of duloxetine. (B) Delta ratios $(\Delta \mathrm{F} 340 / \mathrm{F} 380)$ at maximum responses were calculated from $(\mathrm{A})$. (C) Delta ratios $(\Delta \mathrm{F} 340 / \mathrm{F} 380) 10$ minutes after the addition of $\mathrm{H}_{2} \mathrm{O}_{2}$ were calculated from (A). Results are shown as the
(Supplemental Fig. 1, C and D). To examine the effects of antidepressants on TRPM2 activation, TRPM2/HEK cells were pretreated with antidepressants for 10 minutes, and $\mathrm{H}_{2} \mathrm{O}_{2}$ induced $\left[\mathrm{Ca}^{2+}\right]_{\mathrm{i}}$ increases were then measured in the presence of antidepressants (Fig. 2). $\left[\mathrm{Ca}^{2+}\right]_{\mathrm{i}}$ increases peaked approximately 5 minutes after the application of $\mathrm{H}_{2} \mathrm{O}_{2}$ in duloxetinetreated cells, and these increases then decreased (Fig. 2A). As shown in Fig. 2, B and C, treatment with duloxetine weakly reduced $\left[\mathrm{Ca}^{2+}\right]_{\mathrm{i}}$ increases at the maximum response after the application of $\mathrm{H}_{2} \mathrm{O}_{2}$ (Fig. 2B) and strongly reduced them 10 minutes after the application of $\mathrm{H}_{2} \mathrm{O}_{2}$ (Fig. 2C). Although paroxetine also reduced $\mathrm{H}_{2} \mathrm{O}_{2}$-induced $\left[\mathrm{Ca}^{2+}\right]_{\mathrm{i}}$ increases similar to duloxetine, the inhibitory effects observed were weaker than those of duloxetine (Fig. 2). Imipramine and nortriptyline had no effects on $\left[\mathrm{Ca}^{2+}\right]_{\mathrm{i}}$ increases at the maximum response after the application of $\mathrm{H}_{2} \mathrm{O}_{2}$. On the other hand, imipramine and nortriptyline reduced $\left[\mathrm{Ca}^{2+}\right]_{\mathrm{i}}$ increases 10 minutes after the application of $\mathrm{H}_{2} \mathrm{O}_{2}$. The inhibitory effects of imipramine and nortriptyline were weaker than those of duloxetine (Fig. 2). Agomelatine, milnacipran, and fluvoxamine had no effects on $\mathrm{H}_{2} \mathrm{O}_{2}$-induced $\left[\mathrm{Ca}^{2+}\right]_{\mathrm{i}}$ increases (Fig. 2). Thus, duloxetine exerted the strongest inhibitory effects on $\mathrm{H}_{2} \mathrm{O}_{2}$-induced TRPM2 activation among the antidepressants tested. Therefore, we focused on the effects of duloxetine, particularly its concentration-dependent effects (Fig. 3). Duloxetine concentration-dependently reduced $\mathrm{H}_{2} \mathrm{O}_{2}$-induced $\left[\mathrm{Ca}^{2+}\right]_{\mathrm{i}}$ increases in the maximum response and sustained phase 10 minutes after the application of $\mathrm{H}_{2} \mathrm{O}_{2}$ (Fig. 3A). Maximum inhibitory effects were observed at $10 \mu \mathrm{M}$ in the maximum response and sustained phase (Fig. 3, B and C). To further characterize the inhibitory effects of duloxetine, we investigated the effects of pretreatment times on $\mathrm{H}_{2} \mathrm{O}_{2}$-induced TRPM2 activation. As shown in Fig. 4, pretreatment times did not affect the inhibitory effects of duloxetine.

Reductions in the ADP-Ribose-Induced Current Amplitude in TRPM2/HEK Cells by Duloxetine. Conventional whole-cell patch-clamp recording was used to record the ionic currents generated by TRPM2 channels. As shown in Fig. 5A, $20 \mu \mathrm{M}$ ADP-ribose in the pipette solution gradually evoked the TRPM2 channel current at a holding potential of $-60 \mathrm{mV}$ (Yamamoto et al., 2008), while $10 \mu \mathrm{M}$ duloxetine slowly inhibited the current (Fig. 5A). During the long recording, nonspecific leak currents sometimes appeared and interfered with the objective current. We were able to discriminate between the leak current and TRPM2 channel current based on the response to extracellular $\mathrm{Ca}^{2+}$. The TRPM2 channel current disappeared in $\mathrm{Ca}^{2+}$-free $\left(0 \mathrm{mM} \mathrm{Ca}{ }^{2+}\right.$-containing $)$ external solution (Hara et al., 2002), whereas nonspecific leak currents increased. We confirmed that the inward current was reduced in the absence of extracellular $\mathrm{Ca}^{2+}$ (Fig. 5A). Experiments in which the amplitude of the leak current was more than $10 \%$ of the maximum current were discarded. The inhibitory effects of duloxetine on the current are summarized in Fig. 5B. The remaining current through the TRPM2 channel during the application of $10 \mu \mathrm{M}$ duloxetine was $53.8 \% \pm 3.4 \%$ $(n=8)$. These electrophysiological results indicated that duloxetine inhibited TRPM2 channels.

mean \pm S.E.M. of four experiments. $* P<0.05 ; * * P<0.01$; $* * * P<0.001$ vs. the DMSO group. DMSO, dimethylsulfoxide. 

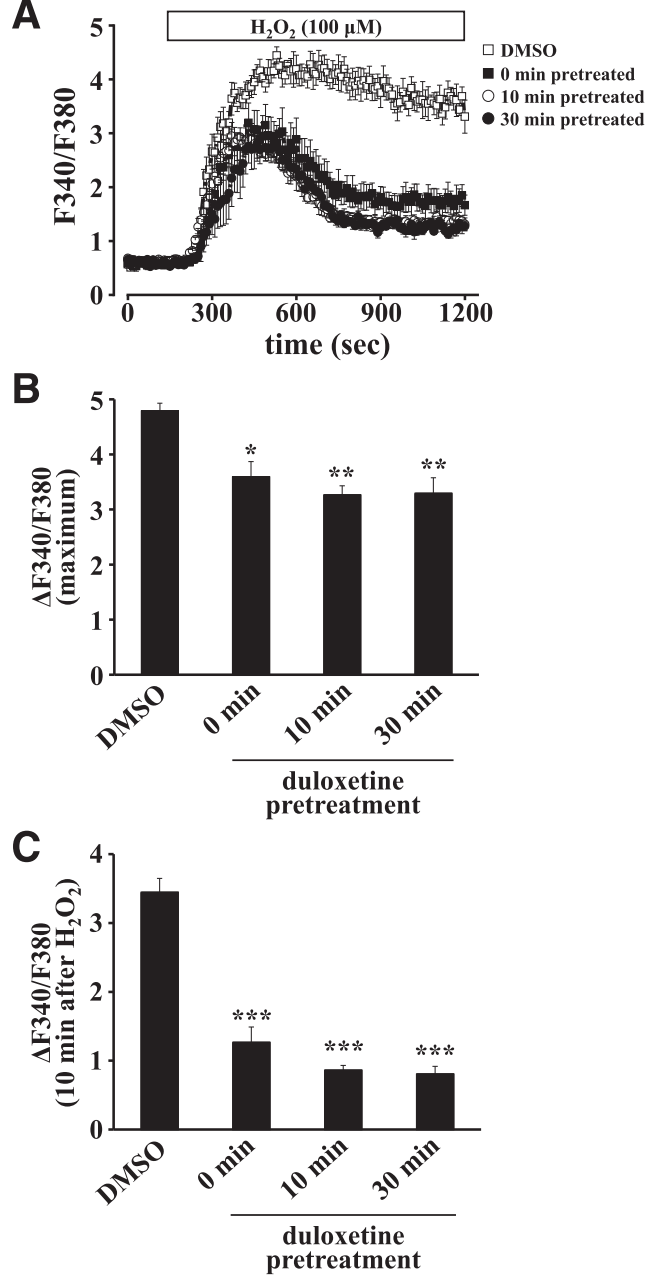

Fig. 4. Effects of the pretreatment time with duloxetine on $\mathrm{H}_{2} \mathrm{O}_{2}$-induced TRPM2 activation. (A) TRPM2/HEK cells were pretreated with $0.1 \%$ DMSO for 10 minutes (DMSO) or $10 \mu \mathrm{M}$ duloxetine for 0,10 , or 30 minutes, and $\mathrm{H}_{2} \mathrm{O}_{2}(100 \mu \mathrm{M})$ was then added in the presence of duloxetine. (B) Delta ratios $(\Delta \mathrm{F} 340 / \mathrm{F} 380)$ at maximum responses were calculated from (A). (C) Delta ratios ( $($ F340/F380) 10 minutes after the $\mathrm{H}_{2} \mathrm{O}_{2}$ treatment were calculated from (A). Results are shown as the mean \pm S.E.M. of four experiments. ${ }^{*} P<0.05$; ${ }^{* *} P<0.01$; ${ }^{* * *} P<0.001$ vs. the DMSO group. DMSO, dimethylsulfoxide.

Effects of Duloxetine on Other Transient Receptor Potential Channels. We examined the effects of duloxetine on other transient receptor potential channels, which are activated by oxidative stress or possess a similar pore region to TRPM2 channels.

TRPA1 and TRPV1 are oxidative stress-sensitive channels that are activated by $\mathrm{H}_{2} \mathrm{O}_{2}$ (Andersson et al., 2008; Takahashi et al., 2008; Chuang and Lin, 2009; Shimizu et al., 2014). The addition of $\mathrm{H}_{2} \mathrm{O}_{2}$ to TRPA1/HEK or TRPV1/HEK cells increased $\left[\mathrm{Ca}^{2+}\right]_{\mathrm{i}}$. In contrast to TRPM2 channels, duloxetine did not affect $\mathrm{H}_{2} \mathrm{O}_{2}$-induced $\left[\mathrm{Ca}^{2+}\right]_{\mathrm{i}}$ increases through TRPA1 channels (Supplemental Fig. 2, A and B) or TRPV1 channels (Supplemental Fig. 2, C and D), respectively.

The TRPM8 channel possesses a similar pore region to the TRPM2 channel (Peier et al., 2002; Kühn et al., 2007) and is activated by menthol and cold temperatures (McKemy et al., 2002; Andersson et al., 2004; Mahieu et al., 2007). The addition of menthol to TRPM8/HEK cells increased $\left[\mathrm{Ca}^{2+}\right]_{\mathrm{i}}$, whereas duloxetine strongly reduced the menthol-induced

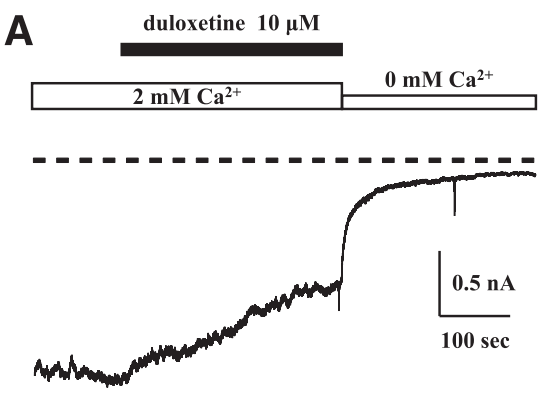

B

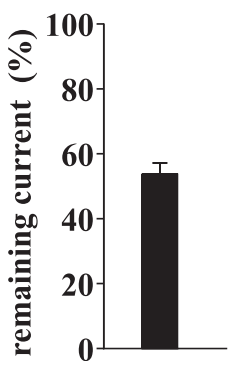

Fig. 5. Duloxetine-induced reductions in the ADP-ribose-induced current amplitude in TRPM2/HEK cells. (A) Typical trace of the TRPM2 channel current induced by $20 \mu \mathrm{M}$ ADP-ribose in the pipette solution at a holding potential of $-60 \mathrm{mV}$. After the maximum current amplitude was reached in $2 \mathrm{mM} \mathrm{Ca}^{2+}$-containing external solution, $10 \mu \mathrm{M}$ duloxetine was applied. The external solution was changed to $\mathrm{Ca}^{2+}$-free external solution. The bars above the current trace depict the application periods of external solutions and duloxetine. (B) TRPM2 currents after the inhibition by $10 \mu \mathrm{M}$ duloxetine are summarized. Results are shown as the mean \pm S.E.M. $(n=8)$.

$\left[\mathrm{Ca}^{2+}\right]_{\mathrm{i}}$ increases mediated by TRPM8 channels (Supplemental Fig. 3, A and B). The exposure of TRPM8/HEK cells to cold temperatures also increased $\left[\mathrm{Ca}^{2+}\right]_{\mathrm{i}}$, and these cold temperature-induced $\left[\mathrm{Ca}^{2+}\right]_{\mathrm{i}}$ increases were attenuated by treatment with duloxetine (Supplemental Fig. 3, C and D).

Protective Effects of Duloxetine on CIR Injury via TRPM2 Inhibition. The effects of duloxetine on CIR injury were examined in the mouse model (Fig. 6). In WT and Trpm2 KO mice, no significant differences were observed in infarct sizes between the 3-hours ischemia group and each shamoperation group. The infarct size in WT mice was markedly increased by reperfusion after ischemia, and this increase was smaller in Trpm2 KO mice. The administration of duloxetine $(10 \mathrm{mg} / \mathrm{kg}$, i.p.) 1 hour before ischemia decreased the infarct size induced by CIR in WT mice, similar to that in Trpm 2 KO mice. Duloxetine did not induce further decreases in the infarct size in Trpm2 KO mice (Fig. 6A). Neurologic scores also showed that reperfusion after cerebral ischemia induced neurologic dysfunction in WT mice, and induction of neurologic dysfunction was reduced by duloxetine treatment or in Trpm2 KO mice (Fig. 6B). However, the administration of duloxetine did not further improve neurologic dysfunction in Trpm2 KO mice (Fig. 6B).

In order for duloxetine to be applied to the treatment of cerebral ischemia to reduce reperfusion injury, it is important for it to also exert protective effects against CIR injury, even when it is administered just before reperfusion therapy. Therefore, duloxetine was administered $(10 \mathrm{mg} / \mathrm{kg}$, i.p. $)$ just before reperfusion, and its effects were investigated (Fig. 7). Similar to the treatment with duloxetine before ischemia, the administration of duloxetine reduced infarct sizes (Fig. 7A) and neurologic scores (Fig. 7B) in WT mice but not in Trpm2 KO mice.

Effects of Milnacipran on CIR Injury. Duloxetine is a serotonin-norepinephrine reuptake inhibitor. To confirm that the protective effects of duloxetine against CIR injury are not mediated by the inhibition of serotonin-norepinephrine reuptake, the effects of another serotonin-norepinephrine reuptake inhibitor (milnacipran) on CIR injury were examined. Milnacipran did not affect infarct sizes induced by CIR (Supplemental Fig. 4). 

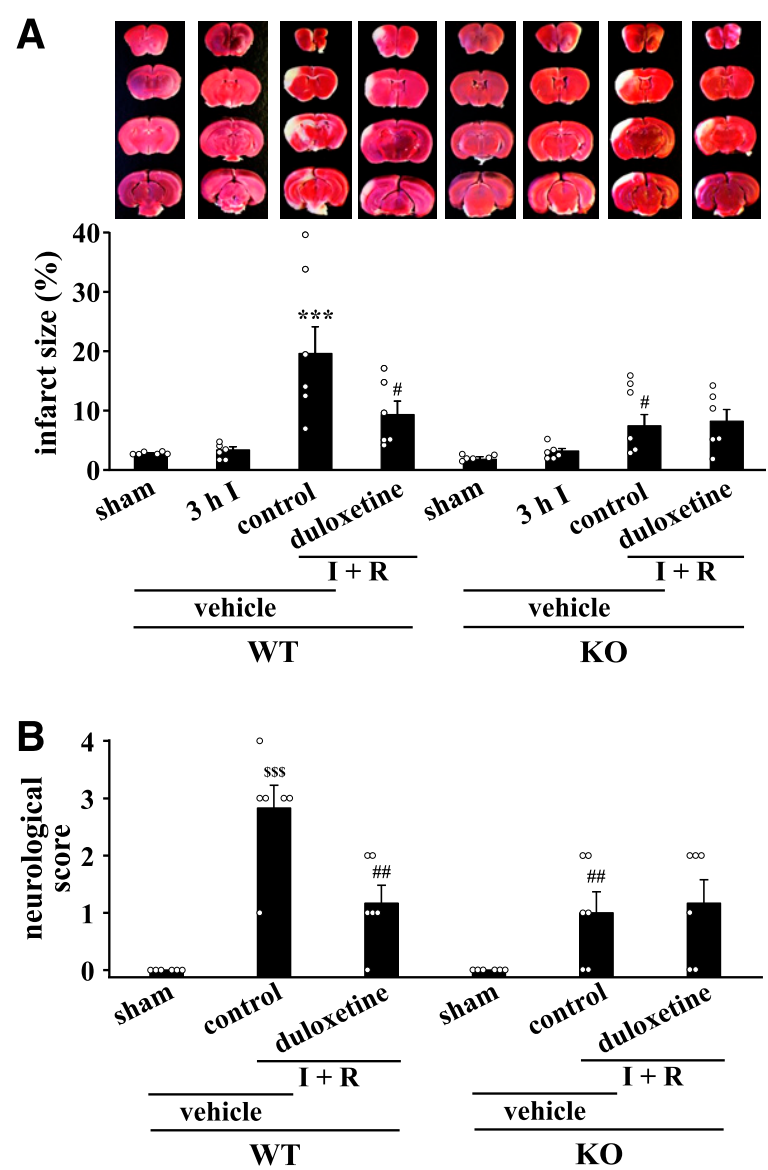

Fig. 6. Protective effects of duloxetine administered before ischemia against CIR injury via TRPM2 inhibition. (A) Coronal sections (thickness of $2 \mathrm{~mm}$ ) showing TTC-stained cerebral tissue of the sham-operation (sham), 3-hour ischemia (3 h I), and vehicle (control) or duloxetine-treated ischemia reperfusion $(\mathrm{I}+\mathrm{R})$ groups in WT and Trpm2 $\mathrm{KO}$ mice. In the sham group and each I + R group, vehicle or duloxetine $(10 \mathrm{mg} / \mathrm{kg}$, i.p.) was administered 1 hour before ischemia, and infarct sizes were measured 21 hours after reperfusion. In the 3 -hour ischemia group, vehicle was administered 1 hour before ischemia, and infarct sizes were then assessed at 3 hours after ischemia. (B) Neurologic scores of the sham and I + R groups in WT and Trpm2 KO mice were assessed 21 hours after reperfusion. Results are shown as the mean \pm S.E.M. $(n=6)$. ${ }^{* * *} P<0.001$ vs. the WT 3 -hour ischemia group; ${ }^{\#} P<0.05$ vs. the WT control group; ${ }^{\# \#} P<0.01$ vs. the WT control group; ${ }^{\$} \$ P<0.001$ vs. the WT sham group. Open circles show the individual values.

\section{Discussion}

Duloxetine is a dual inhibitor of serotonin and norepinephrine reuptake and drives antidepressive efficacy. Akpinar et al. (2014) reported that increases in $\left[\mathrm{Ca}^{2+}\right]_{\mathrm{i}}$ in response to $\mathrm{H}_{2} \mathrm{O}_{2}$ were attenuated in $\mathrm{PC} 12$ cells exposed to long-term treatment with duloxetine, and they suggested that the attenuation of $\mathrm{Ca}^{2+}$ responses is mediated by inhibition of TRPM2 channels and voltage-gated $\mathrm{Ca}^{2+}$ channels. Demirdaş et al. (2017) more recently demonstrated that ADP-ribose-induced TRPM2 currents were reduced in neuronal cells treated with duloxetine for a long time ( 24 hours). Moreover, these findings indicated that treatment of neuronal cells with duloxetine for 24 hours increased antioxidative enzyme levels and decreased the production of ROS that lead to oxidative stress-induced cell damage. However, it currently remains unclear whether duloxetine directly or indirectly inhibits TRPM2 channels by reducing oxidative stress. We
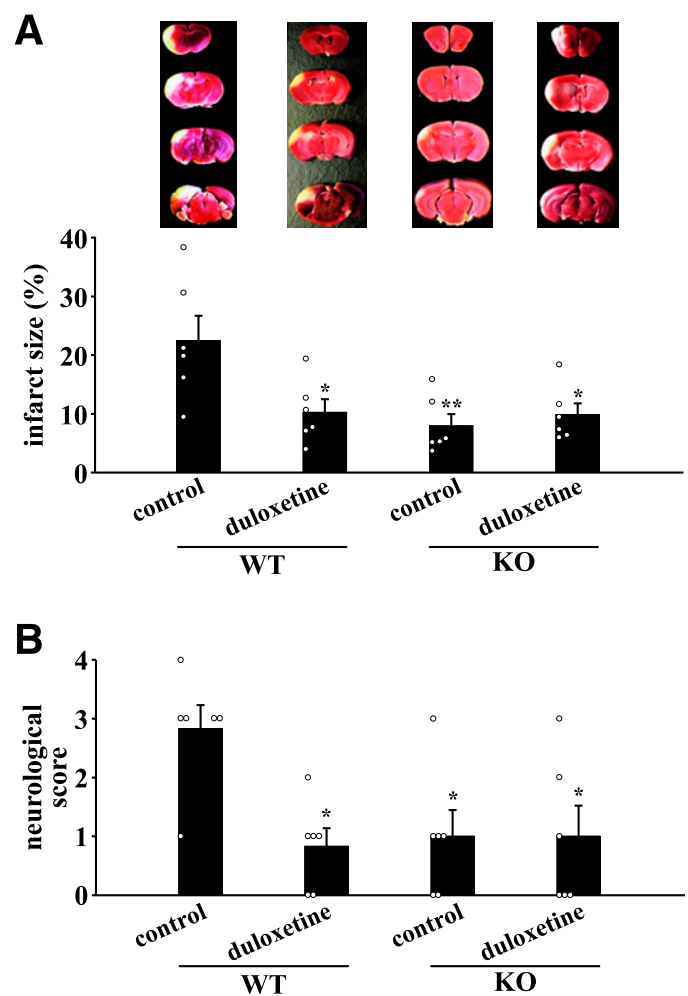

Fig. 7. Protective effects of duloxetine administered just before reperfusion against CIR injury via TRPM2 inhibition. (A) Coronal sections (thickness of $2 \mathrm{~mm}$ ) showing TTC-stained cerebral tissue with ischemia reperfusion in WT and Trpm2 KO mice. Vehicle (control) or duloxetine $(10 \mathrm{mg} / \mathrm{kg}$, i.p.) was administered just before reperfusion, and infarct sizes were then assessed 21 hours after reperfusion. (B) Neurologic scores of each group were assessed 21 hours after reperfusion. Results are shown as the mean \pm S.E.M. $(n=6) . * P<0.05 ; * * P<0.01$ vs. the WT control group. Open circles show the individual values.

showed that among the seven antidepressants tested in this study, duloxetine exerted direct inhibitory effects on TRPM2 channels, with the strongest inhibitory effects being observed on $\mathrm{H}_{2} \mathrm{O}_{2}$-induced TRPM2 activation. Moreover, we demonstrated that duloxetine exerted neuroprotective effects against CIR injury by inhibiting TRPM2 channels.

The inhibitory effects of duloxetine on $\mathrm{H}_{2} \mathrm{O}_{2}$-induced TRPM2 activation were independent of the pretreatment time (0-30 minutes), and they strongly reduced the sustained phase but not the initial phase of TRPM2-mediated $\left[\mathrm{Ca}^{2+}\right]_{i}$ increases. These results prompted us to hypothesize that duloxetine reduces increases in $\left[\mathrm{Ca}^{2+}\right]_{\mathrm{i}}$ through TRPM2 channel inhibition by an open-channel blocking-like mechanism. The results showing that duloxetine reduced ADPribose-induced TRPM2 current during the channel open state support our hypothesis. TRPM8 is also a $\mathrm{Ca}^{2+}$-permeable channel that is activated by cold temperatures and menthol (McKemy et al., 2002; Andersson et al., 2004; Mahieu et al., 2007). The pore region of TRPM8 was previously shown to be similar to that of TRPM2 (Peier et al., 2002; Kühn et al., 2007). Duloxetine suppressed menthol- or cold temperature-evoked TRPM8 activation (Supplemental Fig. 3), suggesting that it attenuates $\mathrm{H}_{2} \mathrm{O}_{2}$-induced TRPM2 activation by affecting its pore region. TRPA1 and TRPV1 are also oxidative stress-sensitive $\mathrm{Ca}^{2+}$ permeable channels (Andersson et al., 2008; Takahashi et al., 2008; Chuang and Lin, 2009; Shimizu et al., 2014). However, duloxetine did not affect $\mathrm{H}_{2} \mathrm{O}_{2}$-induced 


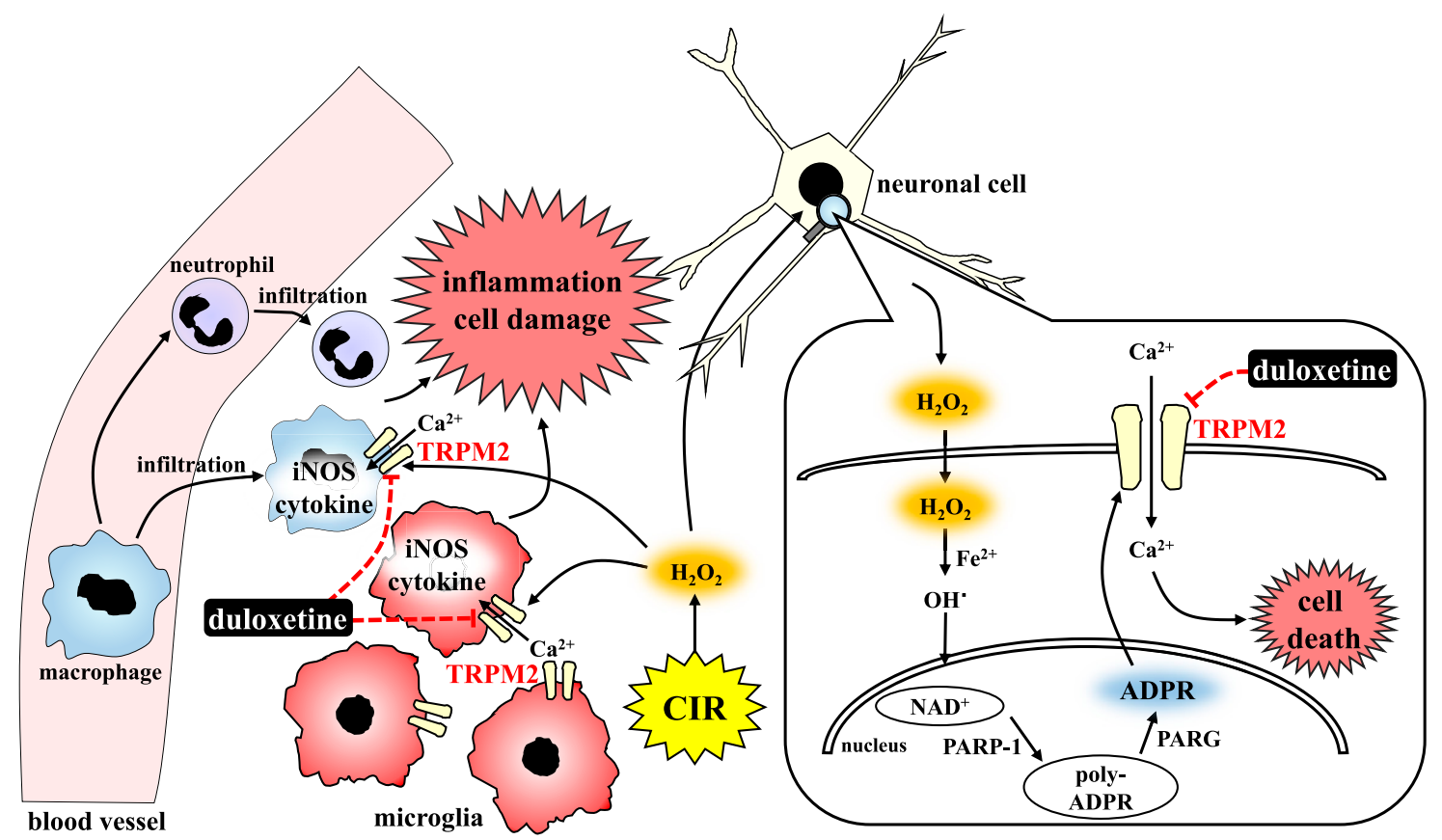

Fig. 8. Prospective mechanisms of duloxetine against CIR injury via TRPM2 inhibition. ADPR, ADP-ribose; iNOS, inducible nitric oxide synthase; PARG, poly(ADP-ribose) glycohydrolase; PARP, poly(ADP-ribose) polymerase.

TRPA1 or TRPV1 activation (Supplemental Fig. 2). The inhibitory effects of duloxetine on $\mathrm{H}_{2} \mathrm{O}_{2}$-induced TRPM2 activation do not appear to be mediated by reductions in oxidative stress, which strongly supports our hypothesis that the attenuation of $\mathrm{H}_{2} \mathrm{O}_{2}$-induced TRPM2 activation by duloxetine may be related to its pore region during the channel open state.

$\mathrm{H}_{2} \mathrm{O}_{2}$-induced TRPM2 activation is enhanced by around body temperature, comparing to $37^{\circ} \mathrm{C}$ (Shimizu et al., 2015). The mechanisms by which body temperature enhances TRPM2 activation are thought to accelerate $\mathrm{H}_{2} \mathrm{O}_{2}$-induced ADP-ribose production. The temperatures in our $\left[\mathrm{Ca}^{2+}\right]_{\mathrm{i}}$ measurement and whole-cell patch-clamp study were $30^{\circ} \mathrm{C}$ and room temperature, respectively. The inhibitory effect of TRPM2 inhibitors, which reduce the production of ADP-ribose, may be influenced by temperature. However, duloxetine inhibits TRPM2 activation by an open-channel blocking-like mechanism. Therefore, temperature does not seem to affect the inhibitory effect of duloxetine.

Reperfusion of the ischemic brain is essential for the rescue of neuronal cells; however, this causes secondary neuronal damage, a phenomenon termed "reperfusion injury," which is characterized by the production of ROS and inflammation leading to neuronal damage (Chan, 1996, 2001). Therefore, the development of drugs to prevent reperfusion injury is important and useful. Accumulating evidence has implicated activation of TRPM2 channels in the aggravation of CIR injury (Jia et al., 2011; Gelderblom et al., 2014; Shimizu et al., 2016; Huang et al., 2017). TRPM2 expression is widely observed in the brain, including neuronal cells (Kaneko et al., 2006; Olah et al., 2009; Verma et al., 2012; Ye et al., 2014; Li et al., 2017) and microglial cells (Kraft et al., 2004; Fonfria et al., 2006; Mortadza et al., 2017), and in macrophages (Yamamoto et al., 2008; Gelderblom et al., 2014). The underlying mechanisms by which TRPM2 channels aggravate brain injury during reperfusion may involve induction of necrotic neuronal cell death by a $\mathrm{Ca}^{2+}$ overload (Ye et al., 2014; Zhan et al., 2016), activation of microglia (Wu et al., 2010; Gelderblom et al., 2014; Shirakawa et al., 2014), and infiltration of macrophages (Gelderblom et al., 2014; Shirakawa et al., 2014). The activated microglia and the infiltrated macrophages secrete inflammatory cytokines and inducible nitric oxide synthase-derived nitric oxide, leading to neuronal cell death and aggravated inflammation (Gelderblom et al., 2009; Wu et al., 2010; Shirakawa et al., 2014). Consistent with these findings, we observed that CIR injury was attenuated in Trpm 2 KO mice. Furthermore, duloxetine exerted neuroprotective effects against CIR injury. Duloxetine may reduce CIR injury by inhibiting TRPM2 activation in neuronal cells, microglia, and infiltrated macrophages during CIR (Fig. 8). Although duloxetine is a serotonin-norepinephrine reuptake inhibitor, another serotonin-norepinephrine reuptake inhibitor (milnacipran) did not reduce CIR injury, suggesting that duloxetine protects the brain against CIR injury independent of its inhibition of serotonin and norepinephrine reuptake. Treatment with duloxetine for 24 hours has been shown to attenuate activation of TRPV1 channels and voltage-gated $\mathrm{Ca}^{2+}$ channels in addition to TRPM2 channels. Importantly, duloxetine did not further reduce CIR injury in Trpm2 KO mice, indicating that it exerts a neuroprotective effect against CIR injury mainly through the inhibition of TRPM2 activation. Treatment of neuronal cells for 24 hours with duloxetine has been reported to increase antioxidative systems, including reduced glutathione/glutathione peroxidase and $\mathrm{Cu}, \mathrm{Zn}$-superoxide dismutase (Akpinar et al., 2014; Lee et al., 2016). Therefore, the induction of antioxidative systems by duloxetine may contribute to inhibition of TRPM2 activation during CIR followed by CIR injury.

Lee et al. (2016) reported that pretreatment with duloxetine for 3 days attenuated ischemia-induced glial activation, 
decreased oxidative stress, and exerted neuroprotective effects against transient global cerebral ischemia. On the other hand, in this study, we showed that CIR injury was reduced by treatment with duloxetine not only 1 hour before ischemia but also just before reperfusion. Therefore, duloxetine has potential as a useful drug in reperfusion therapy for ischemic stroke.

In conclusion, we demonstrated herein that duloxetine exerts inhibitory effects on TRPM2 activation. The mechanisms underlying TRPM2 inhibition appear to be open-channel blocking via an association with its pore region. Moreover, we found that even when duloxetine was administered just before reperfusion, it exerted neuroprotective effects against CIR injury through the inhibition of TRPM2 activation. Therefore, duloxetine has potential as a useful drug in reperfusion therapy for ischemic stroke, and duloxetine may be easily applied to prevent or treat CIR injury from the viewpoint of drug repositioning because it has already been clinically used to treat depressive disorders, diabetic neuropathy, and urinary incontinence.

\section{Acknowledgments}

We thank Takayuki Ishii and Mio Hachiya (Tekiyo Heisei University School of Pharmacy) for technical assistance.

\section{Authorship Contributions}

Participated in research design: Toda, Yamamoto, Shimizu. Conducted experiments: Toda, Yamamoto, Umehara, Wakamori. Performed data analysis: Toda, Yamamoto, Umehara, Wakamori, Shimizu.

Wrote or contributed to the writing of the manuscript: Toda, Yamamoto, Umehara, Mori, Wakamori, Shimizu.

\section{References}

Akpinar A, Uğuz AC, and Nazıroğlu M (2014) Agomelatine and duloxetine synergistically modulates apoptotic pathway by inhibiting oxidative stress triggered intracellular calcium entry in neuronal PC12 cells: role of TRPM2 and voltagegated calcium channels. J Membr Biol 247:451-459.

Andersson DA, Chase HW, and Bevan S (2004) TRPM8 activation by menthol, icilin, and cold is differentially modulated by intracellular pH. J Neurosci 24:5364-5369. Andersson DA, Gentry C, Moss S, and Bevan S (2008) Transient receptor potential $\mathrm{A} 1$ is a sensory receptor for multiple products of oxidative stress. $J$ Neurosci $\mathbf{2 8}$ : $2485-2494$

Belrose JC and Jackson MF (2018) TRPM2: a candidate therapeutic target for treating neurological diseases. Acta Pharmacol Sin 39:722-732.

Buelow B, Song Y, and Scharenberg AM (2008) The poly(ADP-ribose) polymerase PARP-1 is required for oxidative stress-induced TRPM2 activation in lymphocytes. $J$ Biol Chem 283:24571-24583.

Chan PH (1996) Role of oxidants in ischemic brain damage. Stroke 27:1124-1129.

Chan PH (2001) Reactive oxygen radicals in signaling and damage in the ischemic brain. J Cereb Blood Flow Metab 21:2-14.

Chuang $\mathrm{HH}$ and Lin S (2009) Oxidative challenges sensitize the capsaicin receptor by covalent cysteine modification. Proc Natl Acad Sci USA 106:20097-20102.

Demirdaş A, Nazıroğlu M, and Övey IS (2017) Duloxetine reduces oxidative stress, apoptosis, and $\mathrm{Ca}^{2+}$ entry through modulation of TRPM2 and TRPV1 channels in the hippocampus and dorsal root ganglion of rats. Mol Neurobiol 54:4683-4695.

Fonfria E, Marshall IC, Benham CD, Boyfield I, Brown JD, Hill K, Hughes JP, Skaper SD, and McNulty S (2004) TRPM2 channel opening in response to oxidative stress is dependent on activation of poly(ADP-ribose) polymerase. Br J Pharmacol 143:186-192

Fonfria E, Mattei C, Hill K, Brown JT, Randall A, Benham CD, Skaper SD, Campbell CA, Crook B, Murdock PR, et al. (2006) TRPM2 is elevated in the tMCAO stroke model, transcriptionally regulated, and functionally expressed in C13 microglia. $J$ Recept Signal Transduct Res 26:179-198.

Gelderblom M, Leypoldt F, Steinbach K, Behrens D, Choe CU, Siler DA, Arumugam TV, Orthey E, Gerloff C, Tolosa E, et al. (2009) Temporal and spatial dynamics of cerebral immune cell accumulation in stroke. Stroke 40:1849-1857.

Gelderblom M, Melzer N, Schattling B, Göb E, Hicking G, Arunachalam P, Bittner S, Ufer F, Herrmann AM, Bernreuther C, et al. (2014) Transient receptor potential melastatin subfamily member 2 cation channel regulates detrimental immune cell invasion in ischemic stroke. Stroke 45:3395-3402.

Granger DN and Kvietys PR (2015) Reperfusion injury and reactive oxygen species: the evolution of a concept. Redox Biol 6:524-551.

Hamill OP, Marty A, Neher E, Sakmann B, and Sigworth FJ (1981) Improved patchclamp techniques for high-resolution current recording from cells and cell-free membrane patches. Pflugers Arch 391:85-100.
Hara Y, Wakamori M, Ishii M, Maeno E, Nishida M, Yoshida T, Yamada H, Shimizu S, Mori E, Kudoh J, et al. (2002) LTRPC2 $\mathrm{Ca}^{2+}$-permeable channel activated by changes in redox status confers susceptibility to cell death. Mol Cell 9:163-173.

Hashimoto T, Shibata K, Ohata H, Hasumi K, and Honda K (2014) Altered gene expression in an embolic stroke model after thrombolysis with tissue plasminogen activator and Stachybotrys microspora triprenyl phenol-7. J Pharmacol Sci 125: 99-106.

Huang S, Turlova E, Li F, Bao MH, Szeto V, Wong R, Abussaud A, Wang H, Zhu S, Gao X, et al. (2017) Transient receptor potential melastatin 2 channels (TRPM2) mediate neonatal hypoxic-ischemic brain injury in mice. Exp Neurol 296:32-40.

Ishii M, Oyama A, Hagiwara T, Miyazaki A, Mori Y, Kiuchi Y, and Shimizu S (2007) Facilitation of $\mathrm{H}_{2} \mathrm{O}_{2}$-induced A172 human glioblastoma cell death by insertion of oxidative stress-sensitive TRPM2 channels. Anticancer Res 27:3987-3992.

Jia J, Verma S, Nakayama S, Quillinan N, Grafe MR, Hurn PD, and Herson PS (2011) Sex differences in neuroprotection provided by inhibition of TRPM2 channels following experimental stroke. J Cereb Blood Flow Metab 31:2160-2168.

Kaneko S, Kawakami S, Hara Y, Wakamori M, Itoh E, Minami T, Takada Y, Kume T, Katsuki H, Mori Y, et al. (2006) A critical role of TRPM2 in neuronal cell death by hydrogen peroxide. J Pharmacol Sci 101:66-76.

Kraft R, Grimm C, Grosse K, Hoffmann A, Sauerbruch S, Kettenmann H, Schultz G, and Harteneck C (2004) Hydrogen peroxide and ADP-ribose induce TRPM2mediated calcium influx and cation currents in microglia. Am J Physiol Cell Physiol 286:C129-C137.

Kühn FJ, Knop G, and Lückhoff A (2007) The transmembrane segment S6 determines cation versus anion selectivity of TRPM2 and TRPM8. J Biol Chem 282: 27598-27609.

Lee TK, Park JH, Ahn JH, Shin MC, Cho JH, Bae EJ, Kim YM, Won MH, and Lee CH (2016) Pretreated duloxetine protects hippocampal CA1 pyramidal neurons from ischemia-reperfusion injury through decreases of glial activation and oxidative stress. J Neurol Sci 370:229-236.

Li X, Yang W, and Jiang LH (2017) Alteration in intracellular $\mathrm{Zn}^{2+}$ homeostasis as a result of TRPM2 channel activation contributes to ROS-induced hippocampal neuronal death. Front Mol Neurosci 10:414

Longa EZ, Weinstein PR, Carlson S, and Cummins R (1989) Reversible middle cerebral artery occlusion without craniectomy in rats. Stroke 20:84-91.

Mahieu F, Owsianik G, Verbert L, Janssens A, De Smedt H, Nilius B, and Voets T (2007) TRPM8-independent menthol-induced $\mathrm{Ca}^{2+}$ release from endoplasmic reticulum and Golgi. J Biol Chem 282:3325-3336.

McKemy DD, Neuhausser WM, and Julius D (2002) Identification of a cold receptor reveals a general role for TRP channels in thermosensation. Nature 416:52-58.

Mortadza SS, Sim JA, Stacey M, and Jiang LH (2017) Signalling mechanisms mediating $\mathrm{Zn}^{2+}$-induced TRPM2 channel activation and cell death in microglial cells. Sci Rep 7:45032.

Nazıroğlu M, Çelik Ö, Özgül C, Çiğ B, Doğan S, Bal R, Gümral N, Rodríguez AB, and Pariente JA (2012) Melatonin modulates wireless $(2.45 \mathrm{GHz})$-induced oxidative injury through TRPM2 and voltage gated $\mathrm{Ca}\left({ }^{2+}\right)$ channels in brain and dorsal root ganglion in rat. Physiol Behav 105:683-692.

Olah ME, Jackson MF, Li H, Perez Y, Sun HS, Kiyonaka S, Mori Y, Tymianski M, and MacDonald JF (2009) $\mathrm{Ca}^{2+}$-dependent induction of TRPM2 currents in hippocampal neurons. J Physiol 587:965-979.

Peier AM, Moqrich A, Hergarden AC, Reeve AJ, Andersson DA, Story GM, Earley TJ, Dragoni I, McIntyre P, Bevan S, et al. (2002) A TRP channel that senses cold stimuli and menthol. Cell 108:705-715.

Perraud AL, Fleig A, Dunn CA, Bagley LA, Launay P, Schmitz C, Stokes AJ, Zhu Q, Bessman MJ, Penner R, et al. (2001) ADP-ribose gating of the calcium-permeable LTRPC2 channel revealed by Nudix motif homology. Nature 411:595-599.

Shibata K, Hashimoto T, Nobe K, Hasumi K, and Honda K (2010) A novel finding of a low-molecular-weight compound, SMTP-7, having thrombolytic and antiinflammatory effects in cerebral infarction of mice. Naunyn Schmiedebergs Arch Pharmacol 382:245-253.

Shimizu S, Yonezawa R, Hagiwara T, Yoshida T, Takahashi N, Hamano S, Negoro T, Toda T, Wakamori M, Mori Y, et al. (2014) Inhibitory effects of AG490 on $\mathrm{H}_{2} \mathrm{O}_{2}$ induced TRPM2-mediated $\mathrm{Ca}\left({ }^{2+}\right)$ entry. Eur $J$ Pharmacol 742:22-30.

Shimizu S, Yonezawa R, Negoro T, Yamamoto S, Numata T, Ishii M, Mori Y, and Toda $\mathrm{T}$ (2015) Sensitization of $\mathrm{H}_{2} \mathrm{O}_{2}$-induced TRPM2 activation and subsequent interleukin-8 (CXCL8) production by intracellular $\mathrm{Fe}^{2+}$ ) in human monocytic U937 cells. Int J Biochem Cell Biol 68:119-127.

Shimizu S, Yoshida T, Wakamori M, Ishii M, Okada T, Takahashi M, Seto M, Sakurada K, Kiuchi Y, and Mori Y (2006) $\mathrm{Ca}^{2+}$-calmodulin-dependent myosin light chain kinase is essential for activation of TRPC5 channels expressed in HEK293 cells. J Physiol 570:219-235.

Shimizu T, Dietz RM, Cruz-Torres I, Strnad F, Garske AK, Moreno M, Venna VR, Quillinan N, and Herson PS (2016) Extended therapeutic window of a novel peptide inhibitor of TRPM2 channels following focal cerebral ischemia. Exp Neurol 283:151-156.

Shirakawa H, Sakimoto S, Nakagawa T, and Kaneko S (2014) [Pathophysiology of immune cells during the progression of cerebral ischemic injury - involvement of TRPM2-mediated induction of iNOS in microglia/macrophage]. Nippon Yakurigaku Zasshi 144:104-109.

Takahashi N, Mizuno Y, Kozai D, Yamamoto S, Kiyonaka S, Shibata T, Uchida K, and Mori Y (2008) Molecular characterization of TRPA1 channel activation by cysteine-reactive inflammatory mediators. Channels (Austin) 2:287-298.

Toda T, Yamamoto S, Yonezawa R, Mori Y, and Shimizu S (2016) Inhibitory effects of Tyrphostin AG-related compounds on oxidative stress-sensitive transient receptor potential channel activation. Eur J Pharmacol 786:19-28.

Verma S, Quillinan N, Yang YF, Nakayama S, Cheng J, Kelley MH, and Herson PS (2012) TRPM2 channel activation following in vitro ischemia contributes to male hippocampal cell death. Neurosci Lett 530:41-46.

Wehage E, Eisfeld J, Heiner I, Jüngling E, Zitt C, and Lückhoff A (2002) Activation of the cation channel long transient receptor potential channel 2 (LTRPC2) by 
hydrogen peroxide. A splice variant reveals a mode of activation independent of ADP-ribose. J Biol Chem 277:23150-23156.

Wu PF, Zhang Z, Wang F, and Chen JG (2010) Natural compounds from traditional medicinal herbs in the treatment of cerebral ischemia/reperfusion injury. Acta Pharmacol Sin 31:1523-1531.

Yamamoto S, Shimizu S, Kiyonaka S, Takahashi N, Wajima T, Hara Y, Negoro T, Hiroi T, Kiuchi Y, Okada T, et al. (2008) TRPM2-mediated $\mathrm{Ca}^{2+}$ influx induces chemokine production in monocytes that aggravates inflammatory neutrophil infiltration. Nat Med 14:738-747.

Ye M, Yang W, Ainscough JF, Hu XP, Li X, Sedo A, Zhang XH, Zhang X, Chen Z, L $\mathrm{XM}$, et al. (2014) TRPM2 channel deficiency prevents delayed cytosolic $\mathrm{Zn}^{2+}$ accumulation and CA1 pyramidal neuronal death after transient global ischemia. Cell Death Dis 5:e1541.

Zhan KY, Yu PL, Liu CH, Luo JH, and Yang W (2016) Detrimental or beneficial: the role of TRPM2 in ischemia/reperfusion injury. Acta Pharmacol Sin 37:4-12.

Zhang L, Wu J, Duan X, Tian X, Shen H, Sun Q, and Chen G (2016) NADPH oxidase: a potential target for treatment of stroke. Oxid Med Cell Longev 2016:5026984.

Address correspondence to: Dr. Shunichi Shimizu, Division of Pharmacology, Faculty of Pharmaceutical Sciences, Teikyo Heisei University, 4-21-2 Nakano, Nakano-ku, Tokyo 164-8530, Japan. E-mail: s.shimizu@thu.ac.jp 